\title{
Consumption of selected food products by adults representing various body mass categories, during Covid-19 lockdown in Poland
}

\author{
Justyna Leszczak $\mathbb{D}^{1,2 \bowtie}$, Ewelina Czenczek-Lewandowska ${ }^{1,2}$, Justyna Wyszyńska ${ }^{1,2}$, Aneta Weres ${ }^{1,2}$, Bogumił Lewandowski ${ }^{2,3}$ and \\ Joanna Baran ${ }^{1,2}$ \\ (c) The Author(s), under exclusive licence to Springer Nature Limited 2022
}

\begin{abstract}
OBJECTIVES: The study aimed to assess consumption of selected food products by adults with a range of body mass before and during the outbreak of the Covid-19 pandemic as well as identify factors impacting the consumption of selected foods. METHODS: The study was conducted in a group of 690 subjects during the most severe lockdown due to Covid-19 in Poland $(\bar{x}=$ 23 years of age). The dietary assessment was carried out by means of an online survey based on the Food Frequency Questionnaire (FFQ-6). The respondents were asked to provide two answers to each question, one covering a 7-day period before the lockdown and one related to a 7-day period during the lockdown.

RESULTS: During lockdown in the study group there was increase in consumption of sweets and snacks $(p=0.010)$, grain products $(p=0.050)$, fat $(p=0.007)$ as well as alcohol $(p<0.001)$. During the lockdown respondents with normal BMl increased consumption of sweets and snacks $(p=0.011)$, dairy products and eggs $(p=0.034)$, grain products $(p=0.029)$ and alcohol $(p=0.00)$. The group of overweight respondents was found to consume significantly more alcohol $(p=0.022)$, while those with obesity tended to consume more meat $(p=0.002)$, fish $(p<0.001)$ and lower amounts of dairy products $(p=0.003)$. The factors which affected intake of selected food products include age, smoking, place of residence, obesity and education.

CONCLUSIONS: Covid-19 pandemic is significantly related to the change in the frequency of intake of selected products by all adults, irrespective of their BMI. The adverse changes were particularly observed in respondents with overweight and obesity.

European Journal of Clinical Nutrition (2022) 76:1186-1192; https://doi.org/10.1038/s41430-022-01089-3
\end{abstract}

\section{INTRODUCTION}

Obesity is a chronic condition, recognised among risk factors for numerous chronic diseases impacting people's quality of life. These mainly include cancer, cardiovascular diseases, diabetes, osteoarthritis and stroke $[1,2]$. The related preventive activities are adversely affected by the ongoing pandemic of the coronavirus disease. Furthermore, recent studies have shown that infection with the coronavirus produces more severe effects in individuals with excessive body mass, compared to those with normal body mass, and the former seem to face a greater risk of the disease and hospitalisation [3,4]. Obesity is also a major risk factor for mortality due to COVID-19, since it is associated with impaired immune function [5-7]. In this context, importance of healthoriented measures enabling body weight control is particularly emphasised. Moreover, in the course of the pandemic, peoples' behaviours including their eating habits, have been significantly affected due to restrictions and limited physical activity resulting from social distancing, self-isolation, long periods spent at home, and remote rather than traditional mode of work [8, 9]. Those confined to their homes for a long time more frequently feel bored [10], immobilised and anxious [11]. These emotions are linked with a risk of increased intake of unhealthy foods and drinks, including highly-processed fatty foods, sweets and alcohol [12]. During the pandemic people tend to consume unhealthy foods in greater quantities, which is reflected by a growing body of evidence. Few studies, however, have assessed nutritional behaviours in relation to the subjects' current body weight [1315]. We still do not clearly know which body weight group presents the most significant changes in eating habits and what trends are reflected by these changes.

The study aimed to assess consumption of selected food products by adults with a range of body mass before and during the outbreak of the Covid-19 pandemic as well as identify factors impacting the consumption of selected foods.

\section{MATERIALS AND METHODS}

Subjects

Designed as a retrospective pre-post survey, the study was carried out online from 24 March 2020 until 11 April 2020 (period of 19 days) during

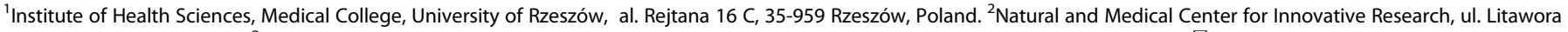
2, 35-310 Rzeszów, Poland. Institute of Medicine, Medical College, University of Rzeszow, al. Rejtana 16 C, 35-959 Rzeszow, Poland. ${ }^{3}$ email: leszczakjustyna.ur@gmail.com 
Table 1. Study group characteristics.

\begin{tabular}{|c|c|c|}
\hline Parameter & $N$ & $\%$ \\
\hline \multicolumn{3}{|l|}{ Age } \\
\hline $18-22$ years & 226 & 32.8 \\
\hline $23-25$ years & 123 & 17.8 \\
\hline $26-36$ years & 175 & 25.4 \\
\hline Over 36 years & 166 & 24.1 \\
\hline \multicolumn{3}{|l|}{ Sex } \\
\hline Female & 470 & 68.1 \\
\hline Male & 220 & 31.9 \\
\hline \multicolumn{3}{|l|}{ BMI category according to $\mathrm{WHO}$} \\
\hline Normal weight & 434 & 62.9 \\
\hline Underweight & 30 & 4.3 \\
\hline Overweight & 167 & 24.2 \\
\hline Obesity & 59 & 8.6 \\
\hline \multicolumn{3}{|l|}{ Current place of residence } \\
\hline Rural area & 298 & 43.2 \\
\hline Urban area $<10,000$ population & 84 & 12.2 \\
\hline Urban area $10-100,000$ population & 136 & 19.7 \\
\hline Urban area $100-300,000$ population & 120 & 17.4 \\
\hline Urban area $300,000-1$ million population & 44 & 6.4 \\
\hline Urban area $>1$ million population & 8 & 1.2 \\
\hline \multicolumn{3}{|l|}{ Education } \\
\hline Secondary & 324 & 47.0 \\
\hline Vocational & 24 & 3.5 \\
\hline Higher & 342 & 49.6 \\
\hline \multicolumn{3}{|l|}{ Smoking } \\
\hline No & 540 & 78.3 \\
\hline From time to time & 82 & 11.9 \\
\hline Yes, between $0-5$ years & 33 & 4.8 \\
\hline Yes, between $5-10$ years & 13 & 1.9 \\
\hline Yes, over 10 years & 22 & 3.2 \\
\hline
\end{tabular}

$N$ number of subjects, \% percent of subjects. the first lockdown announced in Poland, and imposing the most severe restrictions. The participants provided two answers to each question, one covering a 7-day period before the lockdown and one related to a 7-day period during the lockdown. Data published by the Statistical Office confirm that 2,115,578 adults over the age of 18 live in south-eastern Poland. Assuming a $95 \%$ confidence level and a $5 \%$ margin of error, the required sample size should be at least 384 participants. From among the questionnaires sent, 690 respondents were qualified for evaluation on the basis of the inclusion and exclusion criteria. The survey questions were related to the frequency with which the respondents consumed selected food products and additionally they covered personal information, including body weight. Participation in the study was voluntary and anonymous. At the start of the online survey the respondents learned about the study and provided informed consent to participate. Inclusion criteria: residence in Poland, absence of chronic diseases and other conditions that may influence the results of the study, age of study $>18$ years. Exclusion criteria: no consent to the study, medication that may have caused obesity, age under 18 . The study and the method of obtaining informed consent were approved by the Local Bioethics Commission (ref. No. 2/02/2019).

\section{Anthropometric measurements}

Food Frequency Questionnaire (FFQ-6). The research instrument is designed to assess the frequency of consumption of selected food products: sweets and snacks; dairy products and eggs; grain products; fats; fruits; vegetables; meats; fish; sweetened beverages; sugar-free beverages and alcohol. Frequency of product consumption was assessed using a fivepoint scale: (1) never or almost never, (2) 1-3 days/week, (3) more than 3 days/week, (4) once a day, (5) several times a day [16].

Body mass index. Body mass index was calculated based on body height and mass measurements. BMI values were analysed by reference to the World Health Organization classification of obesity: $\mathrm{BMI}<18.5$ underweight, $18.5-24.99$ normal weight, $25-29.99$ overweight, $\geq 30$ obesity [17].

Statistical analysis. Differences between the independent variables were assessed using Mann-Whitney test or Kruskal-Wallis test. Dependent variables were examined using Wilcoxon signed-rank test. Non-parametric tests have been used to compensate for large standard deviations (Wilcoxon and Kruskal-Wallis). The non-parametric methods were applied due to the lack of normal distributions of the variables, examined using Kolmogorov-Smirnov test and the non-fulfilment of the conditions of homogeneity of variance (Levene's test). Additionally, stepwise logistic regression was applied to identify variables significantly related to consumption of the products. The following predictors were defined: sex, age, BMI category, place of residence, education, smoking. Significance

Table 2. Consumption of selected food products before and during the pandemic.

\section{FFQ-6 (5-point scale: (1) never or almost never, (2) 1-3 days/week, (3) more than 3 days/ week, (4) once a day, (5) several times a day}

Sweets and snacks (e.g., sugar, honey, chocolates, baked confectionery, etc.) Dairy products and eggs (milk, yoghurt, cocoa, cheese, scrambled eggs, etc.) Grain products (wholemeal bread, refined bread, groats, etc.)

Fats (oil, butter, margarine, cream, whipping cream, mayonnaise, etc.)

Fruit (fruit, kiwi, citrus fruit, berries, dried fruit, etc.)

Vegetables and seeds (vegetables, green and leafy vegetables, seeds, nuts, etc.)

Meat products (sausage, processed meat, red meat, poultry, etc.)

Fish

Sweetened beverages (fruit nectars, sweetened beverages)

Sugar-free beverages (100\% vegetable, fruit and vegetable as well as fruit juices)

Alcohol

$M$ mean, SD standard deviation.

Wilcoxon signed-rank test.

Bold values represent statistically significant results.

\begin{tabular}{llllll|}
$\begin{array}{l}\text { During } \\
\text { pandemic }\end{array}$ & \multicolumn{3}{l}{$\begin{array}{l}\text { Before } \\
\text { pandemic }\end{array}$} & \multicolumn{2}{l}{$\boldsymbol{l}$} \\
\hline Mean & SD & Mean & SD & & \\
\hline 2.80 & 1.29 & 2.71 & 1.25 & -2.56 & $\mathbf{0 . 0 1 0}$ \\
\hline 3.50 & 1.82 & 3.40 & 1.10 & -1.44 & 0.150 \\
\hline 3.56 & 1.16 & 3.48 & 1.17 & -2.79 & $\mathbf{0 . 0 0 5}$ \\
\hline 3.33 & 1.15 & 3.25 & 1.19 & -2.68 & $\mathbf{0 . 0 0 7}$ \\
\hline 3.42 & 1.16 & 3.38 & 1.14 & -1.43 & 0.152 \\
\hline 3.38 & 1.11 & 3.33 & 1.13 & -1.52 & 0.127 \\
\hline 2.90 & 1.13 & 2.87 & 1.12 & -1.17 & 0.242 \\
\hline 1.82 & 0.76 & 1.84 & 0.76 & -0.84 & 0.400 \\
\hline 1.87 & 1.21 & 1.89 & 1.19 & -0.52 & 0.600 \\
\hline 2.00 & 1.14 & 2.02 & 1.12 & -0.99 & 0.322 \\
\hline 1.78 & 0.99 & 1.50 & 0.72 & -7.37 & $<\mathbf{0 . 0 0 1}$ \\
\hline & & & & & \\
\hline
\end{tabular}




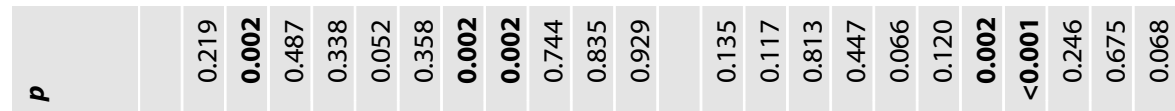

$\frac{\text { ป }}{\frac{1}{5}}$

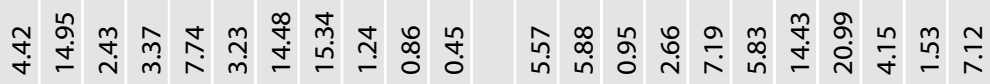

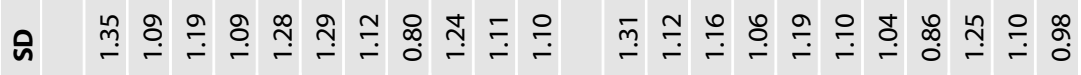

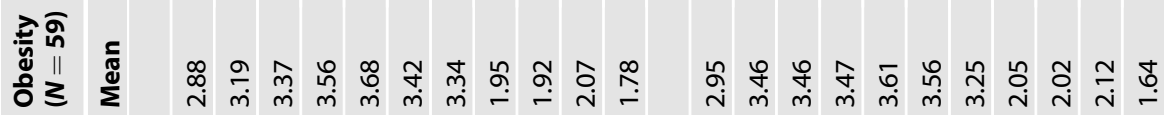

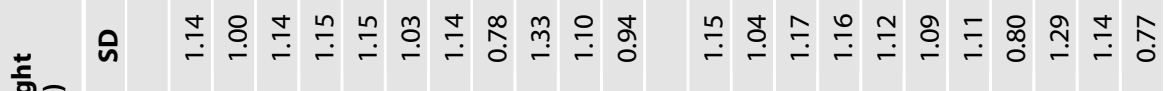

离宅

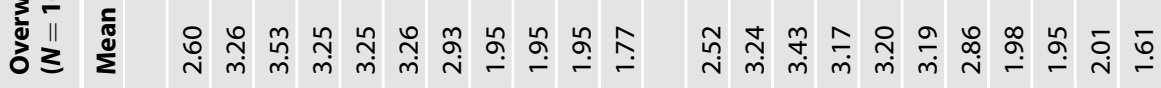

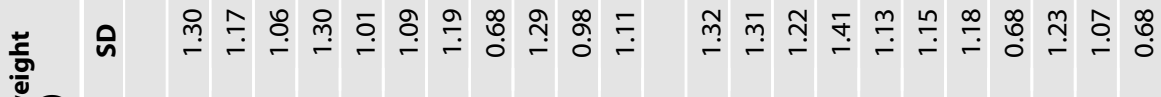

产

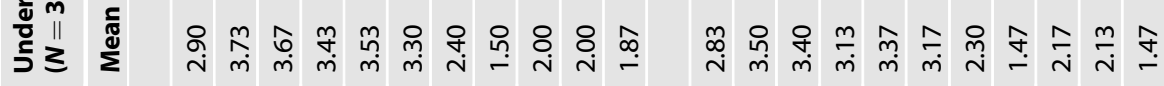

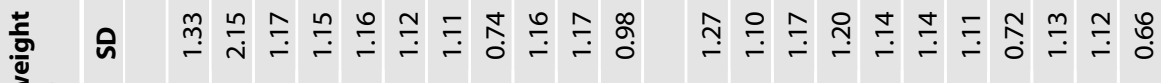

票席

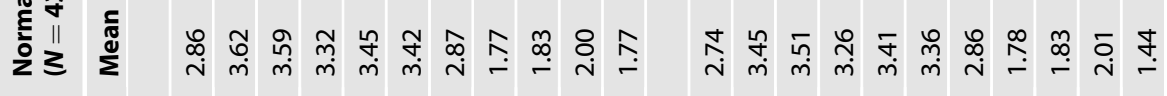

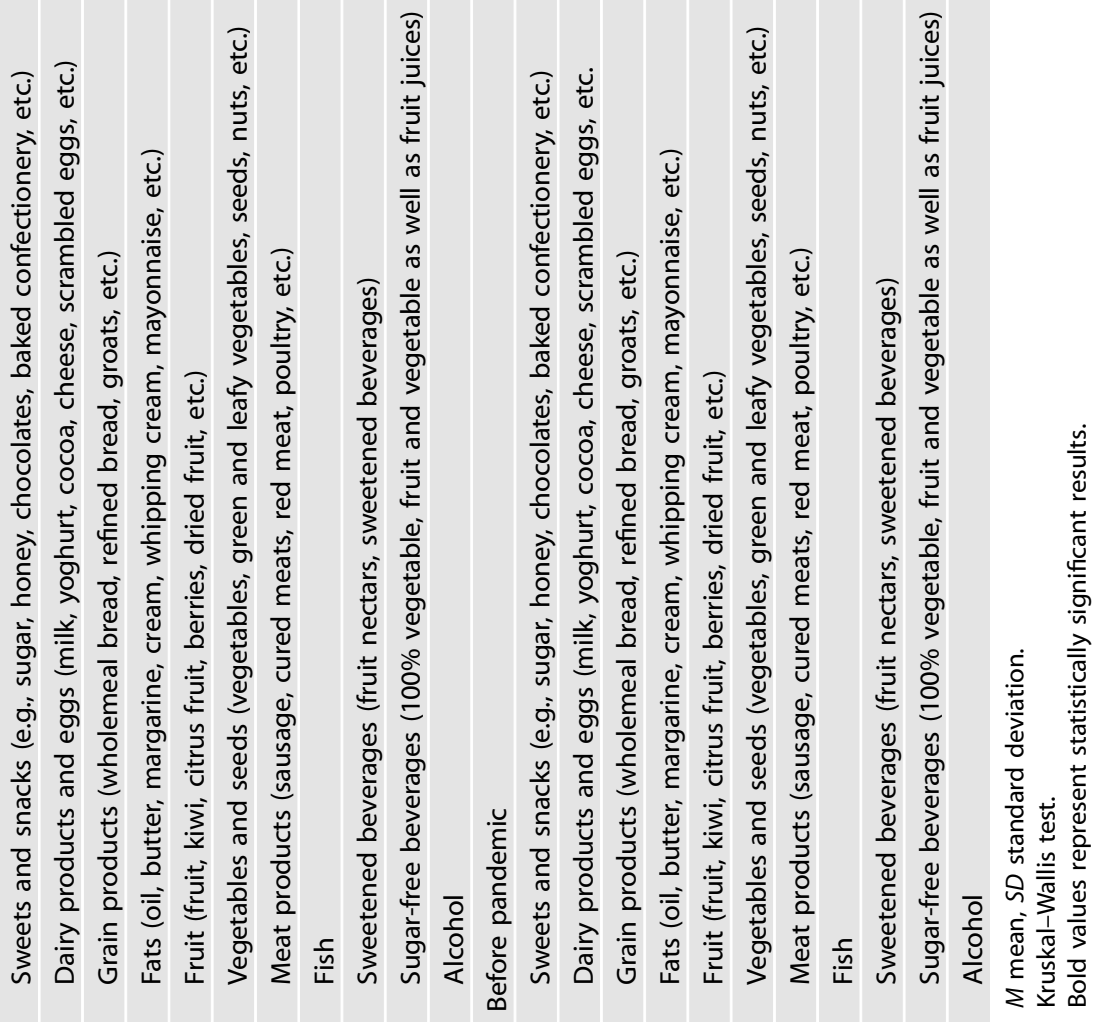


level was assumed in the analyses for $p<0.05$. The calculations were computed using Statistica 13.1 software.

\section{RESULTS}

The study group comprised 470 (68.1\%) females and 220 (31.9\%) males, with mean age of 23 years. Majority of the subjects reported normal body weight (434 respondents; 62.9\%); overweight was identified in 167 respondents (24.2\%), obesity in 59 $(8.6 \%)$, and underweight in 30 respondents (4.3\%). Higher education was reported by a majority, i.e., 342 respondents $(49.6 \%)$, secondary education by 324 respondent $(47 \%)$ and vocational education by 24 respondents (3.5\%) (Table 1 ).

The findings show that during lockdown there was increase in consumption of sweets and snacks $(p=0.010)$, grain products $(p=$ $0.050)$, fats $(p=0.007)$ and alcohol $(p<0.001)$ (Table 2). Compared to women, male respondents reported more frequent intake of meat products (3.16 points), fish (1.90 points), sweetened beverages (1.99 points) as well as alcohol (1.87 points). Consumption of sweets and snacks was higher in respondents below 25 years of age and it decreased with age. Similar relationship was identified with regard to consumption of dairy products and eggs, sweetened beverages as well as alcohol (Table 2).

Analysis of the specific groups representing the varied body mass categories showed that during lockdown those with normal body weight and those with underweight increased intake of dairy products (3.62 versus 3.73). The adults with overweight increased consumption of fish (1.95). The respondents with obesity increased consumption of meat products (3.34) and fish (1.95). A similar trend was identified in this group with regard to the eating habits before the pandemic, as these respondents far more frequently consumed meat products (3.25) and fish (2.05). The data are shown in Table 3.

Comparative analyses of the changes in food intake relative of body mass category showed that during the pandemic respondents with normal BMI significantly increased consumption of sweets and snacks, dairy products and eggs, grain products as well as alcohol. The group of respondents with low BMI was found to significantly increase consumption of fats during the pandemic (from 3.13 to 3.43 points). In the group of overweight respondents, the only significant increase was found in frequency of alcohol consumption, while the respondents with obesity were found to decrease consumption of dairy products (from 3.46 points to 3.19 points) (Table 4).

Results of stepwise logistic regression showed that during the pandemic younger respondents were more frequently drawn to sweets and snacks $(B<0)$. Dairy products were less attractive for smoking respondents $(O R=0.65)$. Fats were more frequently consumed by respondents from rural areas $(O R=0.68)$. During the pandemic meat products were more frequently consumed by respondents with obesity $(O R=1.93)$, and less frequently by underweight $(O R=0.48)$ and overweight respondents $(O R=0.94)$. Sweetened beverages were more attractive for respondents with vocational/secondary education $(\mathrm{OR}=0.66)$ and for smokers $(O R=1.73)$. The latter were also more frequently drawn to sugar-free beverages $(O R=1.50)$. Alcohol was less frequently consumed by younger respondents $(O R=0.97)$ and more frequently by those with higher education $(O R=1.49)$ (Table 5$)$.

\section{DISCUSSION}

The difficult period of the pandemic, including the stringent lockdown, resulted in a change of the respondents' eating habits reflected by consumption of various food products [18-21]. Referring to our own study, there was mainly a significant increase in consumption of sweets, grain products, fats and alcohol which reflects decrease in the quality of the diet followed by adults during the pandemic. The current findings are largely 
Table 5. Variables significantly related to consumption of the products during the pandemic-stepwise logistic regression.

\begin{tabular}{|c|c|c|c|c|c|c|c|}
\hline During pandemic & & B & SE & Wald & df & $p$ & OR (95\% CI) \\
\hline \multirow{2}{*}{$\begin{array}{l}\text { Sweets and snacks (e.g., sugar, honey, chocolates, baked } \\
\text { confectionery, etc.) }\end{array}$} & Age & -0.02 & 0.01 & 10.57 & 1.00 & 0.001 & $0.98(0.97-0.99)$ \\
\hline & Constant & 0.59 & 0.20 & 9.25 & 1.00 & 0.002 & 1.81 \\
\hline \multirow{2}{*}{$\begin{array}{l}\text { Dairy products and eggs (milk, yoghurt, cocoa, cheese, } \\
\text { scrambled eggs, etc.) }\end{array}$} & Smoking & -0.44 & 0.21 & 4.54 & 1.00 & 0.033 & $0.65(0.43-0.97)$ \\
\hline & Constant & 1.25 & 0.10 & 146.48 & 1.00 & $<0.001$ & 3.50 \\
\hline Grain products (wholemeal bread, refined bread, groats, etc.) & Constant & 1.26 & 0.09 & 187.71 & 1.00 & $<0.001$ & 3.51 \\
\hline $\begin{array}{l}\text { Fats (oil, butter, margarine, cream, whipping cream, } \\
\text { mayonnaise, etc.) }\end{array}$ & Place of residence & -0.39 & 0.17 & 5.15 & 1.00 & 0.023 & $0.68(0.49-0.95)$ \\
\hline $\begin{array}{l}\text { Vegetables and seeds (vegetables, green and leafy } \\
\text { vegetables, seeds, nuts, etc.) }\end{array}$ & Constant & 1.05 & 0.09 & 145.87 & 1.00 & $<0.001$ & 2.85 \\
\hline \multirow[t]{3}{*}{ Meat products (sausage, cured meats, red meat, poultry, etc.) } & Sex & 0.44 & 0.18 & 5.93 & 1.00 & 0.015 & $1.55(1.09-2.21)$ \\
\hline & BMI underweight & -0.72 & 0.40 & 3.33 & 1.00 & 0.068 & $0.48(0.22-1.06)$ \\
\hline & BMI overweight & -0.07 & 0.20 & 0.11 & 1.00 & 0.736 & $0.94(0.64-1.37)$ \\
\hline Fish & Constant & -1.83 & 0.11 & 275.75 & 1.00 & $<0.001$ & 0.16 \\
\hline \multirow[t]{3}{*}{ Sweetened beverages (fruit nectars, sweetened beverages) } & Education & -0.42 & 0.19 & 4.75 & 1.00 & 0.029 & $0.66(0.45-0.96)$ \\
\hline & Smoking & 0.55 & 0.21 & 6.56 & 1.00 & 0.010 & $1.73(1.14-2.62)$ \\
\hline & Constant & -1.27 & 0.14 & 80.16 & 1.00 & $<0.001$ & 0.28 \\
\hline \multirow{2}{*}{$\begin{array}{l}\text { Sugar-free beverages ( } 100 \% \text { vegetable, fruit and vegetable as } \\
\text { well as fruit juices) }\end{array}$} & Smoking & 0.41 & 0.20 & 4.02 & 1.00 & 0.045 & $1.50(1.01-2.23)$ \\
\hline & Constant & -1.16 & 0.10 & 131.84 & 1.00 & $<0.001$ & 0.31 \\
\hline \multirow[t]{3}{*}{ Alcohol } & Age & -0.03 & 0.01 & 8.12 & 1.00 & 0.004 & $0.97(0.96-0.99)$ \\
\hline & Education & 0.40 & 0.20 & 3.89 & 1.00 & 0.048 & $1.49(1.00-2.22)$ \\
\hline & Constant & -0.92 & 0.28 & 10.74 & 1.00 & 0.001 & 0.40 \\
\hline
\end{tabular}

$B$ non-standard coefficient, SE standard error, $d f$ degrees of freedom, OR odda ratio, 95\% Cl confidence interval. Bold values represent statistically significant results.

consistent with those reported by other researchers. BłaszczykBębenek et al. observed that during the lockdown the food products which are more frequently consumed include eggs, potatoes, sweets, canned meat and alcohol [22]. Similarly, Cheikh Ismail et al. carried out a study involving 1012 subjects and reported that during the lockdown the participants' eating habits differed from the Mediterranean dietary model and were closer to unhealthy eating patterns [23]. According to Ammar et al., consumption of unhealthy food products was higher during home confinement, and increased from 18.4 to $23.3 \%$ [9]. Likewise, Bogataj Jontez et al. observed adverse effect of the lockdown on the quality of diet, with a decrease in the healthy eating index from 64.59 to 61.08 [24, 25].

The related findings are similar worldwide. It can be anticipated that the unhealthy eating habits observed during COVID-19 pandemic may exacerbate the problem of overweight and obesity which has been scrutinised by specialists worldwide for years [24, 26-28]. Furthermore, it is particularly difficult to counteract this phenomenon during COVID-19 pandemic and because of this the problem should be treated even more seriously now, and efforts should be taken to prevent excessive body weight gain during lockdown. According to Pellegrini et al. during the lockdown the subjects' body weight on average increased by 1.5 kilogram, and a tendency to eat more frequently, and to consume more unhealthy snacks and sweets than before the pandemic, was correlated to a higher body weight gain [29]. The negative changes in nutritional habits may be linked to a tendency to eat in response to stress, boredom, and prolonged confinement at home as well as decreased motivation to exercise. This reflects the complexity of the problem [30-32].
The study shows that changes in the frequency of food intake were observed in the entire study group, irrespective of the subjects' BMI, including the individuals with normal body weight who tended to increase consumption of sweets, snacks, dairy products, eggs, grain products and alcohol. The findings show that the only significant increase in the group of overweight individuals was related to consumption of alcohol, which is an important problem. The largest change in consumption of alcohol was also identified in male respondents and in subjects with higher education. Similarly, Knell et al. showed that during the pandemic subjects aged 35-49 years as well as those 50+, university graduates, and individuals with overweight or obesity were less likely to reduce alcohol consumption [33]. Ferrante et al. reported higher consumption of alcohol in $17 \%$ of the subjects during the pandemic, and the trend was most visible in male subjects and those with higher education, which is consistent with the current findings [34].

The most negative changes were observed in respondents with obesity who reported decreased consumption of dairy products, vegetables, grain products and increased intake of meat and fish. Individuals with obesity are particularly vulnerable to adverse effects of the pandemic and various related factors possibly aggravating their existing health problems; they are also highly susceptible to the coronavirus disease and face a risk of more severe symptoms and complications [35]. Sidor and Rzymski showed that during the pandemic individuals with obesity were particularly likely to decrease intake of vegetables, fruit and legumes, and to increase consumption of fast food, meat and unhealthy snacks. However, more frequent snacking behaviours were presented by all the subjects, irrespective of their BMI $[36,37]$. Coulthard et al. also highlight the differences in food 
intake during the pandemic in individuals with various BMI where a higher BMI was associated with higher emotional eating during the lockdown [38]. Furthermore, according to Almandoz, increased stockpiling of food was reported by nearly one in two respondents, and stress eating was acknowledged by $\sim 62 \%$ of the study participants [39]. Individuals with higher BMI more frequently report negative changes in eating behaviours and physical activity, as well as barriers to body weight control, including lack of motivation and poorer control of eating behaviours [40].

\section{CONCLUSIONS}

The existing pandemic, and most of all the strict lockdowns, are very strong factors which have resulted in a deterioration of adults' eating habits and diet quality. During lockdown the subjects tended to more frequently consume sweets, unhealthy snacks, grain products and alcohol. During the pandemic consumption of dairy products and eggs as well as alcohol were higher in adults with overweight and obesity.

\section{REFERENCES}

1. Matrone A, Ferrari F, Santini F, Elisei R. Obesity as a risk factor for thyroid cancer. Curr Opin Endocrinol Diabetes Obes. 2020;27:358-63. https://doi.org/10.1097/ MED.0000000000000556.

2. Bailey RR, Conroy M. Diabetes and obesity are associated with disability in community-dwelling stroke survivors: a cross-sectional study of 37,955 behavioral risk factor surveillance system respondents. Top Stroke Rehabil. 2021:1-6. https://doi.org/10.1080/10749357.2021.1904537.

3. Yang J, Hu J, Zhu C. Obesity aggravates COVID-19: a systematic review and metaanalysis. J Med Virol. 2021;93:257-61. https://doi.org/10.1002/jmv.26237

4. Hauner $\mathrm{H}$. Secretory factors from human adipose tissue and their functional role. Proc Nutr Soc. 2005;64:163-9. https://doi.org/10.1079/pns2005428.

5. Hussain A, Mahawar K, Xia Z, Yang W, El-Hasani S. Obesity and mortality of COVID-19. Meta-Anal Obes Res Clin Pr. 2020;14:295-300. https://doi.org/10.1016/ j.orcp.2020.07.002.

6. Dietz W, Santos-Burgoa C. Obesity and its implications for COVID-19 mortality. Obesity. 2020;28:1005. https://doi.org/10.1002/oby.22818.

7. Palaiodimos L, Kokkinidis DG, Li W, Karamanis D, Ognibene J, Arora S, et al. Severe obesity, increasing age and male sex are independently associated with worse inhospital outcomes, and higher in-hospital mortality, in a cohort of patients with COVID-19 in the Bronx, New York. Metabolism. 2020;108:154262. https://doi.org/ 10.1016/j.metabol.2020.154262.

8. Di Renzo L, Gualtieri P, Pivari F, Soldati L, Attinà A, Cinelli G, et al. Eating habits and lifestyle changes during COVID-19 lockdown: an Italian survey. J Transl Med. 2020;18:229. https://doi.org/10.1186/s12967-020-02399-5.

9. Ammar A, Brach M, Trabelsi K, Chtourou H, Boukhris O, Masmoudi L, et al. Effects of COVID-19 home confinement on eating behaviour and physical activity: results of the ECLB-COVID19 International Online Survey. Nutrients. 2020;12:1583. https://doi.org/10.3390/nu12061583.

10. Droit-Volet S, Gil S, Martinelli N, Andant N, Clinchamps M, Parreira L, et al. Time and Covid-19 stress in the lockdown situation: time free, «Dying" of boredom and sadness. PLoS ONE. 2020;15:e0236465. https://doi.org/10.1371/journal. pone.0236465.

11. Kaya S, Uzdil Z, Cakiroğlu FP. Evaluation of the effects of fear and anxiety on nutrition during the COVID-19 pandemic in Turkey. Public Health Nutr. 2021;24:282-289. https://doi.org/10.1017/S1368980020003845.

12. Moynihan $A B$, van Tilburg WA, Igou ER, Wisman A, Donnelly AE, Mulcaire JB. Eaten up by boredom: consuming food to escape awareness of the bored self. Front Psychol. 2015;6:369. https://doi.org/10.3389/fpsyg.2015.00369.

13. Muscogiuri G, Barrea L, Savastano S, Colao A. Nutritional recommendations for CoVID-19 quarantine. Eur J Clin Nutr. 2020;74:850-851. https://doi.org/10.1038/ s41430-020-0635-2.

14. Landaeta-Díaz L, González-Medina G, Agüero SD. Anxiety, anhedonia and food consumption during the COVID-19 quarantine in Chile. Appetite. 2021;164: 105259. https://doi.org/10.1016/j.appet.2021.105259.

15. Zabetakis I, Lordan R, Norton C, Tsoupras A. COVID-19: the inflammation link and the role of nutrition in potential mitigation. Nutrients. 2020;12:1466. https://doi. org/10.3390/nu12051466.

16. Wądołowska L. Validation of food frequency questionnaire [FFQ]. Reproducibility assessment. Bromatol Chem Toksyk. 2005;38:27-33.
17. Chernenko A, Meeks $H$, Smith KR. Examining validity of body mass index calculated using height and weight data from the US driver license. BMC Public Health. 2019;19:100. https://doi.org/10.1186/s12889-019-6391-3.

18. Abbas AM, Kamel MM. Dietary habits in adults during quarantine in the context of COVID-19 pandemic. Obes Med. 2020;19:100254. https://doi.org/10.1016/j. obmed.2020.100254.

19. Izzo L, Santonastaso A, Cotticelli G, Federico A, Pacifico S, Castaldo L, et al. An Italian survey on dietary habits and changes during the COVID-19 lockdown. Nutrients. 2021;13:1197. https://doi.org/10.3390/nu13041197.

20. Alhusseini N, Alqahtani A. COVID-19 pandemic's impact on eating habits in Saudi Arabia. J Public Health Res. 2020;9:1868. https://doi.org/10.4081/jphr.2020.1868.

21. Navarro-Cruz AR, Kammar-García A, Mancilla-Galindo J, Quezada-Figueroa G, Tlalpa-Prisco M, Vera-López $O$, et al. Association of differences in dietary behaviours and lifestyle with self-reported weight gain during the COVID-19 lockdown in a University Community from Chile: a cross-sectional study. Nutrients. 2021;13:3213. https://doi.org/10.3390/nu13093213.

22. Błaszczyk-Bębenek E, Jagielski $P$, Bolesławska I, Jagielska A, Nitsch-Osuch $A$, Kawalec P. Nutrition behaviors in Polish adults before and during COVID-19 lockdown. Nutrients. 2020;12:3084. https://doi.org/10.3390/nu12103084.

23. Cheikh Ismail L, Osaili TM, Mohamad MN, Al Marzouqi A, Jarrar AH, Abu Jamous DO, et al. Eating habits and lifestyle during COVID-19 lockdown in the United Arab Emirates: a cross-sectional study. Nutrients. 2020;12:3314. https://doi.org/ 10.3390/nu12113314.

24. Bogataj Jontez N, Novak K, Kenig S, Petelin A, Jenko Pražnikar Z, Mohorko N. The impact of COVID-19-related lockdown on diet and serum markers in healthy adults. Nutrients. 2021;13:1082. https://doi.org/10.3390/nu13041082.

25. Shekar M, Popkin B. Obesity, health and economic consequences of an impending global challenge. International Bank for Reconstruction and Development/The World Bank. https://doi.org/10.1596/978-1-4648-1491-4.

26. Balani $R$, Herrington $H$, Bryant $E$, Lucas $C$, Kim SC. Nutrition knowledge, attitudes, and self-regulation as predictors of overweight and obesity. J Am Assoc Nurse Pr. 2019;31:502-10. https://doi.org/10.1097/JXX.0000000000000169.

27. Nutrition knowledge, attitudes, and self-regulation as predictors of overweight and obesity. J Am Assoc Nurse Pract. 2019;31:511-2. https://doi.org/10.1097/ JXX.0000000000000318.

28. Avgerinos Kl, Spyrou N, Mantzoros CS, Dalamaga M. Obesity and cancer risk: emerging biological mechanisms and perspectives. Metabolism. 2019;92:121-35. https://doi.org/10.1016/j.metabol.2018.11.001.

29. Pellegrini M, Ponzo V, Rosato R, Scumaci E, Goitre I, Benso A, et al. Changes in weight and nutritional habits in adults with obesity during the "Lockdown" period caused by the COVID-19 virus emergency. Nutrients. 2020;12:2016. https:// doi.org/10.3390/nu12072016.

30. Martínez-de-Quel Ó, Suárez-Iglesias D, López-Flores M, Pérez CA. Physical activity, dietary habits and sleep quality before and during COVID-19 lockdown: a longitudinal study. Appetite. 2021;158:105019. https://doi.org/10.1016/j.appet.2020. 105019.

31. Di Renzo L, Gualtieri P, Cinelli G, Bigioni G, Soldati L, Attinà A, et al. Psychological aspects and eating habits during COVID-19 home confinement: results of EHLCCOVID-19 Italian online survey. Nutrients. 2020;12:2152. https://doi.org/10.3390/ nu12072152.

32. Li X, Li J, Qing P, Hu W. COVID-19 and the change in lifestyle: bodyweight, time allocation, and food choices. Int J Environ Res Public Health. 2021;18:10552. https://doi.org/10.3390/ijerph181910552.

33. Knell G, Robertson MC, Dooley EE, Burford K, Mendez KS. Health behavior changes during COVID-19 pandemic and subsequent "Stay-at-Home" orders. Int J Environ Res Public Health. 2020;17:6268. https://doi.org/10.3390/ijerph17176268.

34. Ferrante G, Camussi E, Piccinelli C, Senore C, Armaroli P, Ortale A, et al. Did social isolation during the SARS-CoV-2 epidemic have an impact on the lifestyles of citizens? Epidemiol Prev. 2020;44:353-62. https://doi.org/10.19191/EP20.5-6. S2.137.

35. Kwok S, Adam S, Ho JH, lqbal Z, Turkington P, Razvi S, et al. Obesity: a critical risk factor in the COVID-19 pandemic. Clin Obes. 2020;10:e12403. https://doi.org/ $10.1111 /$ cob.12403.

36. Sidor A, Rzymski P. Dietary choices and habits during COVID-19 lockdown: experience from Poland. Nutrients. 2020;12:1657. https://doi.org/10.3390/nu 12061657.

37. Poelman MP, Gillebaart M, Schlinkert C, Dijkstra SC, Derksen E, Mensink F, et al. Eating behavior and food purchases during the COVID-19 lockdown: a crosssectional study among adults in the Netherlands. Appetite. 2021;157:105002. https://doi.org/10.1016/j.appet.2020.105002.

38. Coulthard H, Sharps M, Cunliffe L, van den Tol A. Eating in the lockdown during the Covid 19 pandemic; self-reported changes in eating behaviour, and associations with BMl, eating style, coping and health anxiety. Appetite. 2021;161:105082. https://doi.org/10.1016/j.appet.2020.105082. 
39. Almandoz JP, Xie L, Schellinger JN, Mathew MS, Gazda C, Ofori A, et al. Impact of COVID-19 stay-at-home orders on weight-related behaviours among patients with obesity. Clin Obes. 2020;10:e12386. https://doi.org/10.1111/ cob.12386.34.

40. Robinson E, Boyland E, Chisholm A, Harrold J, Maloney NG, Marty L, et al. Obesity, eating behavior and physical activity during COVID-19 lockdown: a study of UK adults. Appetite. 2021;156:104853. https://doi.org/10.1016/j. appet.2020.104853.

\section{ACKNOWLEDGEMENTS}

The authors wish to thank all the respondents for their consent to take part in the study in this difficult time of COVID-19 pandemic.

\section{AUTHOR CONTRIBUTIONS}

$\mathrm{JL}$ and $\mathrm{ECL}$ were responsible for designing the review protocol, writing the protocol and report, conducting the search, screening potentially eligible studies, extracting and analysing data, interpreting results, updating reference lists and creating 'Summary of findings' tables, approved the final version. JB and JW were responsible for designing the review protocol and screening potentially eligible studies. They contributed to writing the report, extracting and analysing data, interpreting results and creating 'Summary of findings' tables, approved the final version. AW and BL conducted the meta-regression analyses and contributed to the design of the review protocol, writing the report, arbitrating potentially eligible studies, extracting and analysing data and interpreting results, approved the final version.

\section{COMPETING INTERESTS}

The authors declare no competing interests.

\section{ADDITIONAL INFORMATION}

Correspondence and requests for materials should be addressed to Justyna Leszczak.

Reprints and permission information is available at http://www.nature.com/ reprints

Publisher's note Springer Nature remains neutral with regard to jurisdictional claims in published maps and institutional affiliations. 